\title{
Optimal treatment with hypertonic saline in patients with symptomatic hyponatremia: a perspective from a randomized clinical trial (SALSA trial)
}

\author{
Seon Ha Baek ${ }^{1(i)}$, Sejoong Kim ${ }^{2}$ \\ 'Department of Internal Medicine, Hallym University Dongtan Sacred Heart Hospital, Hwaseong, Republic of Korea \\ ${ }^{2}$ Department of Internal Medicine, Seoul National University Bundang Hospital, Seongnam, Republic of Korea
}

Hyponatremia is the most common electrolyte disturbance in clinical practice ( $14 \%$ to $42 \%$ of all hospitalized patients) and is associated with high mortality [1]. Hypertonic saline is an effective and life-saving treatment for symptomatic hyponatremia [1-3]. Undercorrection of hyponatremia may insufficiently improve fatal complications of cerebral edema, whereas overcorrection from indiscriminate prolonged use of hypertonic saline may result in irreversible neurologic sequelae from osmotic demyelination syndrome (ODS) [4]. American and European guidelines have recommended administering hypertonic saline in small, fixed boluses based on lowquality evidence from small randomized trials and expert opinions $[1,5,6]$. Recently, efficacy and safety of rapid intermittent correction vs slow continuous correction with hypertonic saline in patients with symptomatic hyponatremia: a randomized clinical trial (SALSA trial) involving patients from three general hospitals in Korea from 2016 to 2019 has investigated the efficacy and safety of rapid intermittent bolus (RIB) compared with slow continuous infusion (SCI) with hypertonic saline [7]. This study

Received November 16, 2020; Accepted November 19, 2020

Editor: Tae-Hyun Yoo, Yonsei University, Seoul, Republic of Korea Correspondence: Sejoong Kim

Department of Internal Medicine, Seoul National University Bundang Hospital, 82 Gumi-ro 173beon-gil, Bundang-gu, Seongnam 13620, Republic of Korea. E-mail: sejoong@snubh.org

Copyright () 2020 by The Korean Society of Nephrology

(a) This is an open-access article distributed under the terms of the Creative Commons Attribution Non-Commercial License (http://creativecommons. org/licenses/by-nc-nd/4.0/), which permits unrestricted non-commercial use, distribution, and reproduction in any medium, provided the original work is properly cited. aimed to introduce the results of the SALSA trial and discuss a bolus regimen of hypertonic saline as an optimal treatment in patients with symptomatic hyponatremia.

This prospective, investigator-initiated, multicenter, open-label, randomized controlled trial enrolled 178 patients aged $>18$ years with symptomatic hypoosmolar hyponatremia and glucose-corrected serum sodium (sNa) level $\leq 125 \mathrm{mmol} / \mathrm{L}$. The primary outcome was incidence of overcorrection at any given period, defined as increased sNa level by $>12$ or $18 \mathrm{mmol} / \mathrm{L}$ within 24 or 48 hours, respectively. Secondary and post hoc outcomes included the efficacy and safety of treatment approaches. Patients (mean age, $73.1 \pm 12.2$ years; male, $44.9 \%$; and mean sNa concentration, $118.2 \pm 5.0 \mathrm{mmol} / \mathrm{L}$ ) were randomly assigned to the RIB $(\mathrm{n}=87)$ or SCI $(\mathrm{n}=$ 91) group. No significant difference was observed in the incidence of overcorrection between the two groups (RIB vs. SCI: $17.2 \%$ [15/87] vs. $24.2 \%$ [22/91]; absolute risk difference, $-6.9 \%$ [ $95 \%$ confidence interval, CI: $-18.8 \%$ to $4.9 \%], P=0.256)$. With regard to safety outcomes, no ODS events occurred in either group. The RIB group showed a lower incidence of relowering treatment than the SCI group (41.4\% [36/87] vs. 57.1\% [52/91]; absolute risk difference, $-15.8 \%$ [95\% CI: $-30.3 \%$ to $-1.3 \%$ ], $P=0.035$ ), and the magnitude of the difference between RIB and SIC (15.8\%) translates to 6.3 as a number needed to treat (NNT) to prevent relowering treatment. The groups did not differ in efficacy of increasing sNa concentration or improving symptoms; however, RIB showed better efficacy in achieving target correction rate within 1 hour (32.2\% [28/87] vs. $17.6 \%$ [16/91], absolute risk difference $14.6 \%$ [95\% CI: $2.0 \%$ to $27.2 \%$ ], $P=0.024$ ). The difference 


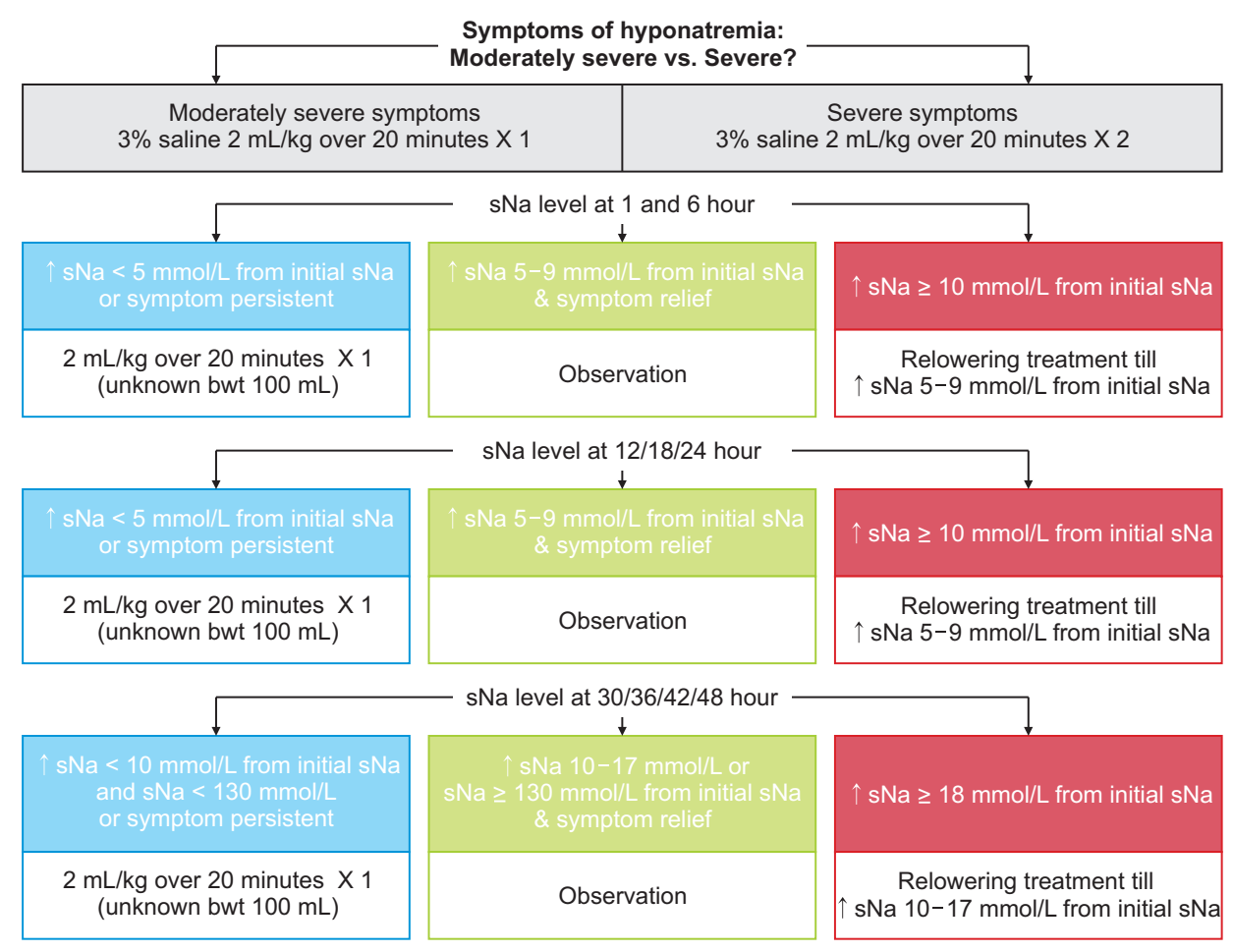

Figure 1. Rapid intermittent bolus correction with hypertonic saline. Reused from the article of Baek et al [7] with original copyright holder's permission. bwt, body weight; sNa, serum sodium. between RIB and SCI (14.6\%) translates into an NNT of 6.8 to achieve the target correction rate within 1 hour. Results of this randomized clinical trial indicate that both RIB and SIC therapies using hypertonic saline for treatment of symptomatic hyponatremia are effective and safe, without a significant difference in the overcorrection risk. However, RIB had a lower incidence of therapeutic relowering treatment and better efficacy in achieving sNa within 1 hour than SCI. RIB could be the preferred treatment for symptomatic hyponatremia, consistent with the current consensus guidelines. Moreover, RIB regimens are simple and require lower medical burden owing to the omission of the need for calculation.

We recommend rapid intermittent bolus correction as shown in Fig. $1[1,5,7]$. First, patients should be classified into two groups based on severity of hyponatremia: moderately severe (nausea, headache, drowsiness, general weakness, and malaise) and severe (vomiting, stupor, seizure, and coma [Glasgow coma scale, $\leq 8]$ ) symptomatic hyponatremia. Second, in cases of moderately severe symptoms, one shot of $2 \mathrm{~mL} / \mathrm{kg} \mathrm{3 \%}$ saline intravenous infusion should be administered for 20 minutes. In cases of severe symptoms, two shots of $2 \mathrm{~mL} / \mathrm{kg} \mathrm{3 \%}$ saline infusion should be administered for 40 minutes. Third, an additional injection of $2 \mathrm{~mL} / \mathrm{kg} \mathrm{3 \%}$ saline infusion should be repeatedly administered for 20 minutes every 6 hours until the initial sNa level increase by $5-9 / 10-17 \mathrm{mmol} / \mathrm{L}$ within 24/48 hours or until symptom relief. This weightbased approach, different from the American and European guidelines (fixed 100-150-mL infusion volumes of $3 \%$ hypertonic saline) $[1,5]$, may effectively increase $\mathrm{sNa}$ concentration and help prevent overcorrection because Koreans have a smaller physique than Westerners. Based on the reported experience in the SALSA trial, bolus treatment could be the standard treatment for symptomatic hyponatremia. Moreover, we encourage experts in the field of electrolytes to perform another randomized controlled trial to achieve more high-quality evidence [8].

\section{Conflicts of interest}

The authors have no conflicts of interest to declare.

\section{References}

[1] Spasovski G, Vanholder R, Allolio B, et al.; Hyponatraemia Guideline Development Group. Clinical practice guideline on diagnosis and treatment of hyponatraemia. Eur J Endocrinol 2014;170:G1-G47.

[2] Ayus JC, Krothapalli RK, Arieff AI. Treatment of symptom- 
atic hyponatremia and its relation to brain damage. A prospective study. N Engl J Med 1987;317:1190-1195.

[3] Adrogué HJ, Madias NE. Hyponatremia. N Engl J Med 2000; 342:1581-1589.

[4] Sterns RH. Treatment of severe hyponatremia. Clin J Am Soc Nephrol 2018;13:641-649.

[5] Verbalis JG, Goldsmith SR, Greenberg A, et al. Diagnosis, evaluation, and treatment of hyponatremia: expert panel recommendations. Am J Med 2013;126(10 Suppl 1):S1-S42.

[6] Hoorn EJ, Zietse R. Diagnosis and treatment of hyponatre- mia: compilation of the guidelines. J Am Soc Nephrol 2017; 28:1340-1349.

[7] Baek SH, Jo YH, Ahn S, et al. Risk of overcorrection in rapid intermittent bolus vs slow continuous infusion therapies of hypertonic saline for patients with symptomatic hyponatremia: the SALSA randomized clinical trial. JAMA Intern Med 2020 Oct 26 [Epub]. Doi: 10.1001/jamainternmed.2020.5519.

[8] Yoo TH. KRCP's past and future path. Kidney Res Clin Pract 2020;39:233-235. 